\title{
Requirements for installation of pedestrian crossings in Lithuania
}

\author{
Aja Tumavičè, Igoris Kravcovas, Edita Juodvalkienè \\ Vilnius Gediminas Technical University Faculty of Environmental Engineering Road Research Institute, Linkmeny str. 28, \\ VI corps, 5th floor, 08217 Vilnius, Lithuania
}

\begin{abstract}
Pedestrian in pedestrian crossing thinks that he is absolutely safe. But not all existing pedestrian crossings can ensure safe crossing of the street. Therefore, is mandatory to install pedestrian crossings, which will be friendlier for pedestrians and for other road users.

Unfortunately, until now in Lithuania there were no detail installation standards adopted specially for pedestrian crossings. Also, there was no clear vision when and how to install pedestrian crossings as well as traffic calming measures close to them. This article presents analysis of "Pedestrian crossings installation rules" which were prepared and adopted in 2012 for the use in Lithuania.
\end{abstract}

Keywords: non-signalized pedestrian crossing; pedestrian passing; signalized pedestrian crossing; pedestrian bridge; pedestrian underpass.

\section{Introduction}

All over the world the pedestrian injury constitutes considerable part of all injury that occurs during the traffic accidents. Also the pedestrian traumas are very hard [1]. In the cities $1 / 4$ of the traffic accidents, participated by pedestrians, happen at the pedestrian crossings or nearby [2]. In Lithuania 2009-2012 about 30\% of all injured or perished in traffic accidents were pedestrians [3].

Non-signalized pedestrian crossings (further "pedestrian crossings") are the one of the most dangerous places in the street. Crossing the street at the pedestrian crossing people wrongly think they are safe. Verily, it is only marked place where pedestrian can cross the street and where vehicle drivers ought to let him do this. But unfortunately, not always drivers notice pedestrians and stops, therefore, it is possible to install the pedestrian crossing only if the safe traffic is guaranteed for all participants. And if it is not possible, pedestrian crossing must be not installed at all and another type of street crossing facility must be chosen.

At the same time the safety of pedestrian in the streets could be implemented using traffic legislation, information of traffic participants and training, also by constructing pedestrian friendly vehicles and properly installing pedestrian crossing (ex. to warrant proper visibility).

In order to reduce the number of perished pedestrians also vehicle speed must be reduced at the pedestrian crossings [1]. Traffic signs or other indirect measures (training, speed control, police fines, etc.) must be used for this purpose.

Construction of speed bumps (5-7 cm high) reduce the vehicle speed and increase safety of pedestrians [4]. The vehicle speed at the pedestrian crossing is lower if the distance between the speed cushion and the crossing is bigger. Even bigger impact has the high of speed cushion [5]. Speed bumps are the proper speed reduction measure, but their construction doesn't make any influence on individual driving at the high and unsafe speed. So the safety means must be various training, documentation and punishment [4]. Also pedestrians must be obliged to cross the streets only at the marked crossings, because if they do not so, introduced pedestrian-safety-related measures will not be effective [6]. The more pedestrians cross the streets beyond market crossing the higher the traffic accident risk will be [7].

Refuge island improves pedestrian safety, reduces pedestrian stress, also reduces vehicle speed and intercept the overtake of vehicles [8]. The pedestrians are intended to wait at the crossing until they will be able to cross the street. Construction of wider refuge island could make the pedestrian patience higher and prolong waiting time. Also refuge island could be wrapped to enforce pedestrians not to go in straight line. It is recommended to construct refuge islands more than $1.5 \mathrm{~m}$ width [9]. Other authors suggest the refuge island width must be more than $1.75 \mathrm{~m} \mathrm{[8].}$

Corresponding author: Aja Tumavičè. E-mail address: aja.tumavice@vgtu.lt

http://dx.doi.org/10.3846/enviro.2014.170

(C) 2014 The Authors. Published by VGTU Press. This is an open-access article distributed under the terms of the Creative Commons Attribution License, which permits unrestricted use, distribution, and reproduction in any medium, provided the original author and source are credited. 
The number of traffic accidents depends on traffic intensity and driving speed [7], so it is very important to take into account these parameters then pedestrian crossing is designed. Also, pedestrian, when he cross the street, interrupts traffic flow and so reduces its capacity. At the same time the time-wasting of pedestrians is lowered because patient pedestrians most often follow more aggressive ones. Also, then there are more waiting pedestrians, the vehicle drivers reduce speed and improves conditions for pedestrians to cross the street [10].

In all the cases pedestrian crossing is the higher risk zone, especially if it is constructed not at the right place and without using other traffic calming measures or using them improperly.

\section{Traffic Safety Situation in Lithuania}

One of the biggest traffic problems in Lithuania remains the exceeding of speed limits. For example, in 2012 of all 355333 times then traffic regulation was broke, the exceeding of speed limit were recorded in 109917 times. It means nearly every 4 traffic rules breach is connected with speed exceeding. Also, the growing number of speed limit exceeding could be traced [11].

During 2012 in Lithuania 3173 traffic accidents were happed, 3712 traffic participants were injured, 301 perished, 526 of them were happened at pedestrian crossing: 540 people were injured and 17 perished [3]. So, every 6 traffic accident in 2012 happened at pedestrian crossing.

The highest number of traffic accidents in which participate pedestrians happens during the cold period (October January), when the visibility and traffic conditions are bad. For example in 2012 during these 4 months $49.64 \%$ of pedestrian connected traffic accidents happened (Fig. 1), and the highest number of perished were during November - even $24.76 \%$ of all perished in 2012 [3].

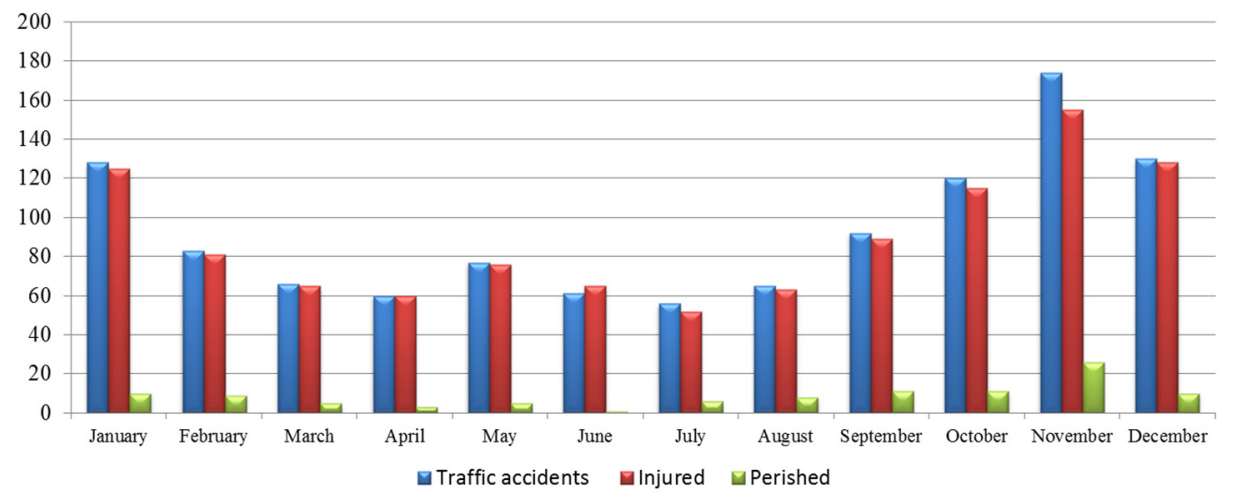

Fig. 1. Pedestrian traffic accident distribution according to 2012 months

The statistics of traffic accidents is influenced also by the day time. For ex. in 2012 during the bright time of the day 2.5 time more traffic accidents happen then during the dark time, also there 2 times more injured pedestrians (Fig. 2). However the results of traffic accidents are harder during the dark part of the day, for ex. the number of perished pedestrians is 2 times higher than during the bright part of the day [12].

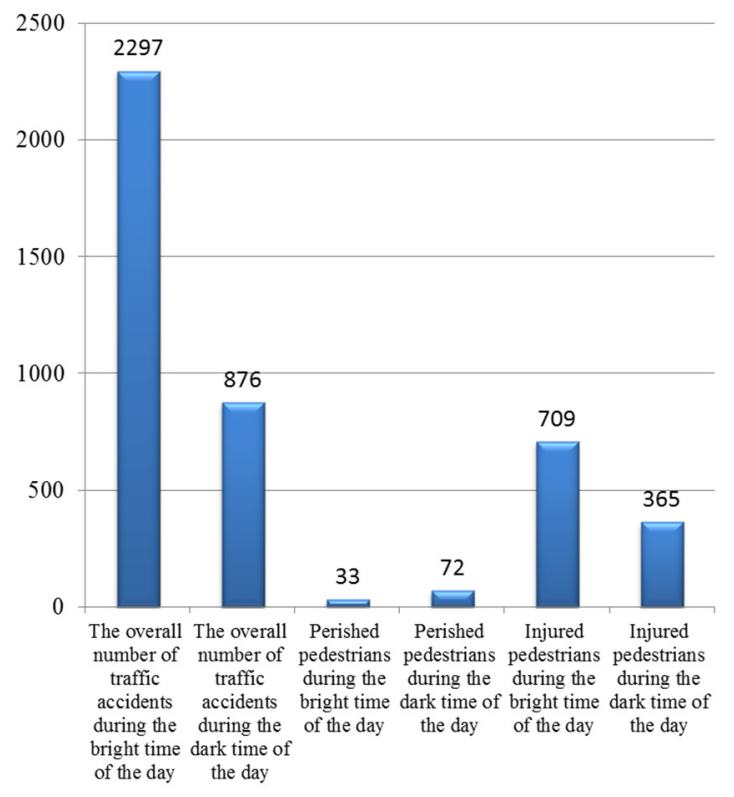

Fig. 2. Distribution of traffic accidents and injured pedestrians according to day time in 2012 
It is very important to illuminate the pedestrian crossing in a way that not only the crossing could be clearly seen but also the surroundings and the pedestrians themselves at the crossing. Fig. 3 shows the unlit pedestrian crossing. It is clear that street illumination is not enough for pedestrians to be noticed. Fig. 4 shows properly illuminated pedestrian crossing. The difference is obvious.

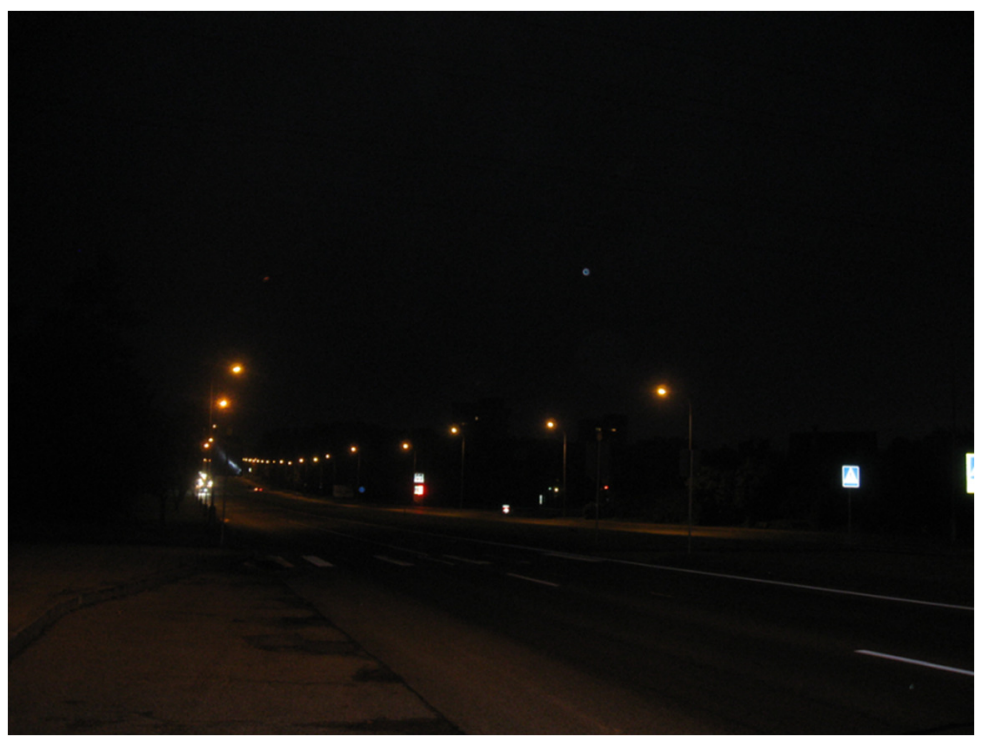

Fig. 3. Pedestrian crossing at highway (A2 category), traffic flow in 2 lanes at each direction, $\mathrm{V} \leq 60 \mathrm{~km} / \mathrm{h}$ speed Vilnius, Geležinio Vilko street in 2012 [12]

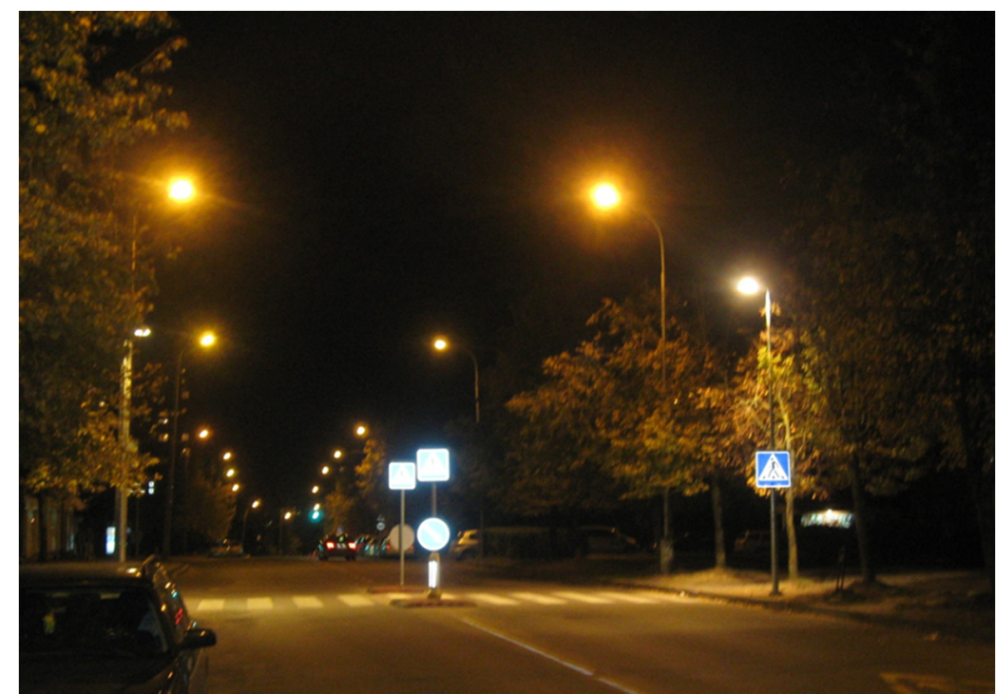

Fig. 4. Properly illuminated pedestrian crossing. Vilnius, Didlaukio street in 2012

In order to secure traffic at pedestrian crossing, installation of it must be done properly, so the proper law should be implemented. Unfortunately, now the pedestrian crossing design and installation standards are not clear and detail, also, not always used in pedestrian crossing design and installation. It determines that the pedestrian then crossing the street could not be always sure about his safety. The most significant problems of standards were as follows:

- There were no generalizing standard for design and installation of pedestrian crossings;

- There were no clearance then and how pedestrian crossing must be installed and which safety measures must be chosen.

The lack of unified pedestrian crossing installation regulation caused the installation implementation not according to the common principles, but to local conditions. Therefore part of pedestrian crossings is not safe - hard recognized, without enough visibility, not properly signed, installed at the wrong places, etc.

According to modern pedestrian traffic installation regulation, innovations and experience to safeguard crossing the street pedestrians from injury, also to unify the regulation of pedestrian crossing installation, the new technical and legal standard must be prepared for the design and installation of pedestrian crossings. 


\section{Traffic Safety Situation in Lithuania}

In 2012 Lithuanian Road Administration under the Ministry of Transport and Communications prepared and approved Pedestrian crossings installation rules. The new distribution method of pedestrian crossings was presented (from the safest up to less safe):

- Pedestrian bridge;

- Pedestrian underpass;

- Signalized pedestrian crossing;

- Pedestrian crossing;

- Pedestrian passing.

The safest way to cross the street is at different grade. Otherwise, this kind of pedestrian crossing is expensive to install, it covers big area and if the traffic intensity is high it doesn't serve the purpose. Non-signalized pedestrian crossing is rather cheaper to construct, but even it is installed properly, it wouldn't be the safest way, so it could be chosen only by strictly defined conditions and to satisfy certain requirements. Also the new kind of pedestrian crossing - pedestrian passing - the unmarked place at the street where pedestrians has no priority right was suggested. As pedestrians has no priority, they will act more responsible and cautiously.

The document presents attitudes to warrant traffic safety at the pedestrian crossing and to prevent cases of unsafe pedestrian crossings installation. The criteria, according what it could be clear, in which conditions and which pedestrian crossing measures must be used. These criteria show when and in which conditions additional traffic calming measures must be used. The clear methods of pedestrian crossing choice are also presented (Fig. 5).

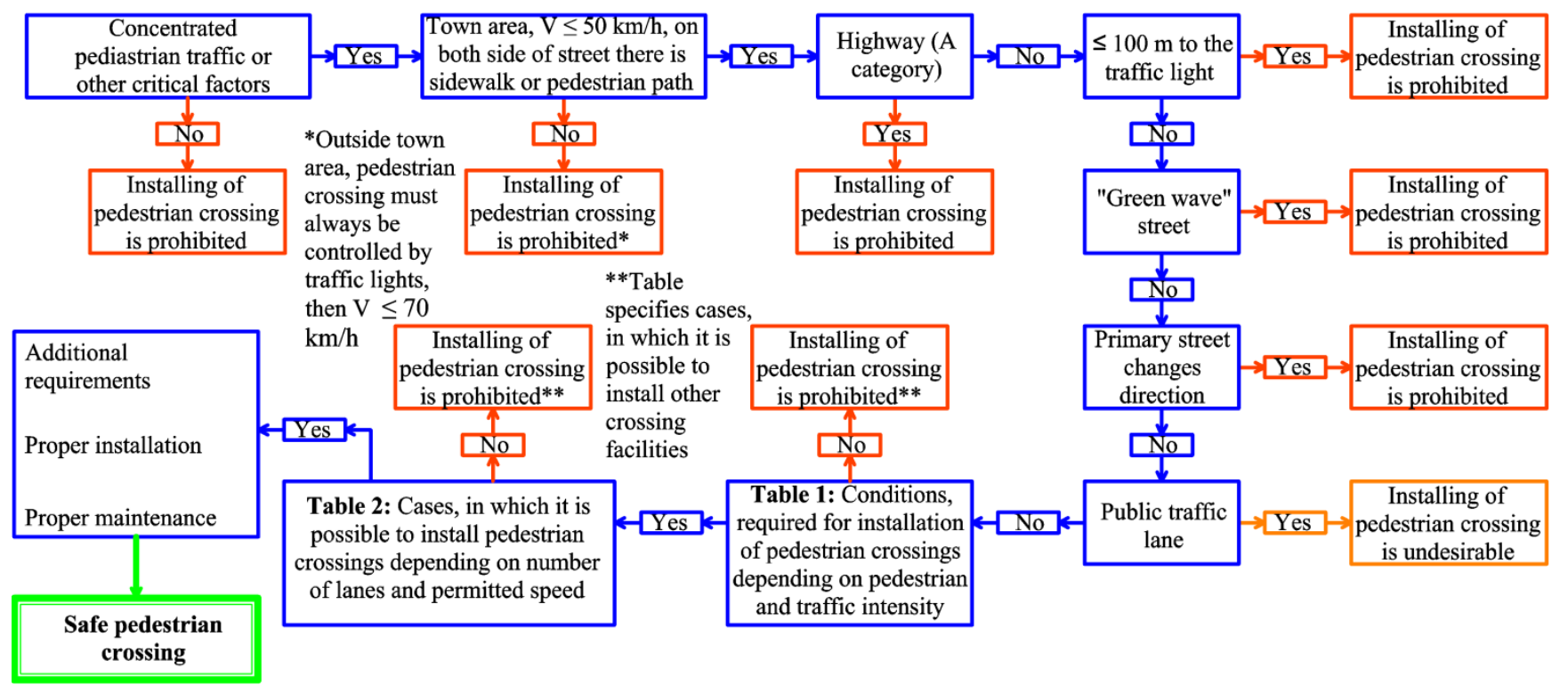

Fig. 5. Diagram of pedestrian crossings installation

The new Pedestrian crossings installation rules proposed vertical deflection and horizontal deflection traffic calming measures and presented their division:

- Vertical deflection speed reduction measures (speed table, sinusoidal profile speed hump, speed hump, speed cushion);

- Horizontal deflection speed reduction measures (narrowed street by using refuge islands, narrowed street from one or both sides, narrowed street up to one-way street width, chicane).

At the same time rules for the choice of these measures were presented. For example at the street with 2 lanes for each direction the pedestrian crossing must be installed using traffic calming measures.

As the refuge islands are one of the most effective measure to cross the street safe at the non-signalized pedestrian crossing the new regulation was presented describing at what conditions they must be installed (traffic flow in 2 lanes at each direction, $30<\mathrm{V} \leq 50 \mathrm{~km} / \mathrm{h}$ speed) or it is recommended to install (traffic flow in 1 lane at each direction). Also world tendency was taken into account and recommended width $2.00-2.50 \mathrm{~m}$ of refuge island was presented. More narrow refuge islands $(\geq 1.50 \mathrm{~m}$ ) could by constructed only in exceptional cases (the lack of building area then speed limit is $\leq 30 \mathrm{~km} / \mathrm{h}$, etc.).

Strict regulation was presented to warrant mutual driver's and pedestrian's visibility in time. The minimal visibility distances were presented as well as good pedestrian crossing visibility at different time of the day, also compulsory crossing illumination, separate from all street illumination. 


\section{Conclusions}

1. Pedestrian crossing doesn't guaranty safe street crossing especially if it is installed in inappropriate way or at the wrong place. So, if there is need to build pedestrian crossing, it must be done in a way to ensure as much as possible more safe traffic for all traffic participants. If there is no possibility to ensure this, pedestrian crossing must be not installed at all.

2. Pedestrian crossing installation rules presents new division (5 types) of street crossing measures and detail requirements for pedestrian crossing installation. Also the criteria for additional traffic calming measures were formed.

3. It was declared that pedestrian crossing must be installed only at settlements where the speed maximum $\leq 50 \mathrm{~km} / \mathrm{h}$ and only where sidewalk or pedestrian path is at the both sides of the street. Outside the town areas pedestrian crossing must be constructed only controlled by traffic lights then speed maximum is $\leq 70 \mathrm{~km} / \mathrm{h}$.

4. The new conditions of pedestrian crossing installation according to traffic intensity, number of traffic lanes and permissible maximum speed were proposed. If the traffic flow is more than 2 traffic lanes at each direction it is forbidden to install pedestrian crossing or pedestrian passing. Only signalized pedestrian crossing or grade separated pedestrian crossings could be constructed.

5. The new regulation was proposed that pedestrian crossing must be seen from far away, so driver could be ready to reduce the speed. Therefore it must be illuminated brighter than the street.

\section{References}

[1] Abdulrazzaq, H.; Zarour, A.; El-Menyar, A.; Majid, M.; Al Thani, H.; Asim, M.; Latifi, R.; Maull, K. 2012. Pedestrians: the daily underestimated victims on the road, International journal of injury control and safety promotion, 37-41.

[2] Dago, A.; Tiia, R.; Harri, R. 2007. Investigating Drivers' Behaviour at Non-Signalised Pedestrian Crossings, The Baltic Journal of Road and Bridge Engineering 2(3): 118-118.

[3] Statistics of fatal and injury cases at road accidents in Lithuania.

[4] Antić, B.; Pešić, D.; Vujanić, M.; Lipovac, K. 2013. The influence of speed bumps heights to the decrease of the vehicle speed - Belgrade experience, Safety Science 57: 303-312. http://dx.doi.org/10.1016/j.ssci.2013.03.008

[5] Johansson, C.; Rosander, P.; Leden, L. 2011. Distance between speed humps and pedestrian crossings: does it matter?, Accident; analysis and prevention 43(5): 1846-1851. http://dx.doi.org/10.1016/j.aap.2011.04.020

[6] Yannis, G.; Kondyli, A.; Georgopoulou, X. 2013. Investigation of the impact of low cost traffic engineering measures on road safety in urban areas, International journal of injury control and safety promotion, 37-41.

[7] Elvik, R.; Sørensen, M. W. J.; Nævestad, T. 2013. Factors influencing safety in a sample of marked pedestrian crossings selected for safety inspections in the city of Oslo, Accident; analysis and prevention 59: 64-70. http://dx.doi.org/10.1016/j.aap.2013.05.011

[8] Čarský, J.; Mačerinskienè, A. 2012. Modern ways of designing roads through, Journal of civil engineering and management, 37-41.

[9] Rosenbloom, T.; Pereg, A. 2012. A within-subject design of comparison of waiting time of pedestrians before crossing three successive road crossings, Transportation Research Part F: Traffic Psychology and Behaviour 15(6): 625-634. http://dx.doi.org/10.1016/j.trf.2012.05.011

[10] Jin, S.; Qu, X.; Xu, C.; Wang, D. 2013. Dynamic characteristics of traffic flow with consideration of pedestrians' road-crossing behaviour, Physica A, Statistical Mechanics and its Applications 392(18): 3881-3890.

[11] Lietuvos keliu policijos tarnyba (Lithuanian traffic police information). Available from Internet: http://www.lkpt.lt/lt/

[12] Vaitkus, A.; Tumavičè, A. 2013. Atpažistama ir sauganti pẻsčiụjų perèja, Lietuvos keliai 2: 52-55. 